\title{
Aplikasi Kamus ViKA sebagai Visualitator Kosakata Bahasa Arab untuk Pembelajar Pemula
}

\author{
Lia Sunarti, Ernawati, Marja'i Affan \\ Institut Agama Islam Negeri Salatiga \\ liasunarti3@gmail.com
}

DOI: http://dx.doi.org/10.18326/lisania.v1i1.37-55

\begin{abstract}
This research aims to produce a digital dictionary ViKA (Visualitation by Creation and Action) as media for for beginner learners to understand the meaning of Arabic vocabulary according the morphology (Creation) and syntax (Action). This Research and Development uses quantitative data for the analysis with the independent variables "ViKA Dictionary" and the dependent variable "the ineffectiveness of existing dictionaries and the effectiveness of ViKA dictionary. ViKA Dictionary is tested to 50 of $1^{\text {st }}$ semester students of Arabic Education at State Institute for Islamic Studies Salatiga, with the data is obtained through Pre-ViKA and Post-ViKA questionnaires and interviews. Signification test of the data is done by two-tailed test to accept an alternative hypothesis "That students of Arabic Education 1st Semester are beginner learners and existing dictionaries give understanding of detail meaning of Arabic vocabulary yet and ViKA dictionary is effective for use", or reject the null hypothesis "That $1^{\text {st }}$ semester students of Arabic Education 1st are not beginner learners and existing dictionaries give understanding of detail meaning of Arabic vocabulary and ViKA dictionary is ineffective for use ". The result of signification test according to the rules decision of two-tailed test is whether the $\mathrm{H}_{1}$ is accepted and $\mathrm{H}_{0}$ is rejected. So "ViKA Dictionary is effective being used by beginner Arabic learners".
\end{abstract}

Keywords: ViKA Dictionary, Visualizer, Arabic Vocabulary

\begin{abstract}
Abstrak
Penelitian ini bertujuan untuk menghasilkan kamus digital ViKA (Visualizing by Creation and Action) sebagai media bantu bagi pembelajar pemula dalam memahami makna kosakata bahasa Arab dari segi morfologi atau sharaf (Kreasi) dan sintaksis atau nahwu (Aksi). Penelitian R and D ini menggunakan analisa data kuantitatif dengan variabel bebas "Kamus ViKA" dan variabel terikatnya kurang efektifnya kamus yang sudah ada dan keefektifan kamus ViKA. Kamus ViKA ini diujikan kepada 50 mahasiswa PBA IAIN Salatiga semester 1, dengan data untuk setiap variabel didapatkan melalui angket dan wawancara Pra-ViKA dan Pasca-ViKA. Data tersebut kemudian diuji signifikasi dengan tes dua-ekor untuk menerima hipotesis alternatif bahwa mahasiswa PBA Semester 1 adalah pembelajar pemula dan kamus yang sudah ada belum memahamkan makna kosakata bahasa Arab secara mendetail dan kamus ViKA efektif untuk digunakan, atau menolak hipotesis nihilnya bahwa mahasiswa PBA Semester 1 bukan pembelajar pemula dan kamus yang sudah ada
\end{abstract}


mampu memahamkan makna kosakata bahasa Arab secara mendetail dan kamus ViKA belum efektif untuk digunakan. Setelah uji signifikansi dilakukan dan mendapatkan hasilnya, maka sesuai dengan tata aturan pengambilan keputusan tes dua-ekor hasil penelitiannya adalah Ha diterima dan Ho ditolak. Sehingga dapat disimpulkan bahwa kamus ViKA efektif untuk digunakan bagi pembelajar bahasa Arab pemula.

Kata Kunci : Kamus ViKA, Visualitator, Kosakata Bahasa Arab

\section{Pendahuluan}

Kemajuan teknologi yang begitu pesat membuat berbagai kalangan berlomba-lomba untuk menciptakan suatu produk yang bernilai tinggi dan bermanfaat bagi masyarakat luas, tidak lain adalah mahasiswa. Tuntutan pekerjaan untuk hasil yang memuaskan dengan waktu yang singkat merupakan salah satu sebab dimana masyarakat harus mulai terbiasa untuk menggunakan produk-produk teknologi yang canggih, termasuk dalam dunia pendidikan. Tuntutan untuk menggunakan teknologi dalam proses belajar mengajar di lembaga pendidikan, menjadi suatu wacana yang penting untuk segera ditindak lanjuti. Khususnya bagi para pengajar yang harus mampu berkreasi dengan teknologi untuk meningkatkan kualitas materi yang diajarkan dan pemahaman peserta didik, tentunya hal tersebut mencakup semua bidang pengajaran, salah satunya adalah bahasa Arab.

Bahasa arab memiliki makna-makna yang tersembunyi untuk diungkap maksudnya, kekayaan tersebut membuat bahasa Arab memiliki banyak cabang ilmu untuk dipelajari, dua diantaranya adalah nahwu dan shorof. Nahwu dan sharaf disebut sebagai ayah dan ibu bahasa Arab, dengan memahaminya kita akan mudah memahami makna yang dimaksud dari kosakata tersebut, baik ketika berdiri sendiri maupun tersusun dalam kalimat. Tentunya, bagi penutur non-Arab kamus menjadi media penting untuk digunakan dalam memahami makna kosakata bahasa Arab.

Banyak kamus yang bisa dipakai untuk mengetahui arti dan makna dari kosakata bahasa Arab. Baik kamus manual, seperti kamus Al-Munawwir atau kamus digital, seperti kamus Mufid dan lain sebagainya. Sayangnya, kamus-kamus tersebut baik yang manual maupun digital hanya menampilkan hakikat makna kata saja tidak disertai dengan penjelasan dari kaidah nahwu dan sharafnya, padahal nahwu dan sharaf adalah kunci yang 
sangat penting untuk memahami makna suatu kosakata bahasa arab secara kompleks. Hal tersebut tentunya menyebabkan pembelajar pemula kesulitan untuk memahami kosakata bahasa Arab.

Maka melalui penelitian ini, penulis mencoba membuat aplikasi kamus digital bahasa Arab yang mampu menampilkan makna kosakata tersebut yang dikaitkan dengan kaidah ilmu nahwu dan sharafnya secara bersamaan. Kamus tersebut berfungsi untuk memvisualisasi pembelajar pemula melalui pengkreasian kosakatanya dengan kaidah ilmu sharaf dan pengaksian atau penerapan kosakata tersebut dalam kalimat yang kemudian ditelaah dari kaidah ilmu nahwunya. Agar memudahkan para pembelajar bahasa Arab pemula menemukan makna kosakata dalam kamus sekaligus dapat mengetahui dan memahami makna yang ditinjau dari kaidah nahwu dan sharafnya.

\section{Metodologi Penelitian}

Jenis penelitian dalam penelitian ini adalah $R \& D$ dengan analisis data kuantitatif. Menurut Sugiono, langkah-langkah penelitian dan pengembangan meliputi: identifikasi masalah, pengumpulan informasi, desain produk, validasi desain, perbaikan desain, uji coba produk, revisi produk, uji coba pemakaian, revisi produk tahap akhir, dan produksi massal (Emzir, $2008: 271)$.

Peneliti melakukan studi kasus terlebih dahulu sebelum membuat desain kamus ViKA. Pembuatan desain kamus ViKA ini merupakan Project Emphasis (proyek tujuan) untuk membuat desain kamus yang sesuai kebutuhan (Comprehensive Design). Pembuatan desain kamus yang sesuai kebutuhan diketahui setelah melakukan analisis data (Content Analysis), yang datanya didapatkan dari angket Pra-ViKA.

Setelah desain kamus dibuat, maka dilakukanlah evaluasi terhadap kamus tersebut setelah melalukan uji coba produk (Evaluation) kepada dosen pembimbing dan temanteman. Evaluasi dilakukan berdasarkan dari masukan yang diberikan oleh dosen dan teman-teman untuk kemudian melakukan perbaikan. Setelah dilakukan perbaikan terhadap kamus, maka kemudian melakukan uji coba pemakaian kepada sampel (Field Observation). Dari uji coba terhadap sampel ini akan didapatkan data terkait tidak atau 
efektifnya kamus ViKA dari angket Pasca ViKA. Data yang didapat dari angket pra dan pasca ViKA dikuatkan dengan melakukan wawancara (In-Depth Interview).

Dalam menentukan populasi, diperlukan informasi-informasi yang valid, sehingga akan didapatkan objek yang tepat sasaran untuk uji suatu produk. Dalam hal ini peneliti memutuskan bahwa populasi untuk uji coba kamus ViKA adalah mahasiswa Pendidikan Bahasa Arab Fakultas Tarbiyah dan Ilmu Keguruan (FTIK) IAIN Salatiga. Namun mengingat waktu, biaya, dan tenaga yang kurang memadai untuk uji coba seluruh populasi, maka atas pertimbangan dari tim dan pembimbing peneliti memutuskan untuk melakukan sampling dengan cara sampling purposif. Sampling purposif merupakan sampling pertimbangan, yang pengambilan sampel didasarkan pada pertimbangan peneliti dan ahli (Sudjana, 2005: 168). Dalam hal ini, peneliti dan atas saran pembimbing memutuskan untuk melakukan sampling dengan cara ini. Karena, sampling seperti ini juga merupakan cara yang bisa digunakan untuk menghasilkan data yang representatif.

Adapun mengenai sumber data didapatkan dari angket dan hasil wawancara terhadap sampel yang telah peneliti tetapkan, yaitu mahasiswa jurusan Pendidikan Bahasa Arab Fakultas Tarbiyah dan Ilmu Keguruan (FTIK) IAIN Salatiga semester 1 berjumlah 50 mahasiswa, yang terdiri dari 2 kelas yaitu kelas A dan kelas B. Selanjutnya peneliti melakukan analisis data dalam dua tahap, yang pertama adalah dengan melakukan pengkodingan (coding) dan pengkategorisasian (categorizing) terhadap data baik berupa hasil angket maupun wawancara. Yang kedua adalah melakukan pengujian data hasil studi kasus yang muncul secara statistik.

Untuk menguji data kategori Pra ViKA yaitu "bahwa kamus yang ada selama ini belum bisa memahamkan makna secara mendetail dan kamus manual kurang fleksibel untuk digunakan" digunakan uji signifikasi dua-ekor, sebab menggunakan z-score dari suatu statistik S pada kedua ujung atau ekor distribusinya. Dengan uji signifikasi ini akan didapatkan dasar motivasi kesesuaian yang valid terkait kebutuhan untuk dibuatnya produk kamus ViKA ini. Uji signifikasi tersebut juga akan digunakan untuk menguji data kategori Pasca ViKA yaitu "bahwa kamus ViKA efektif untuk digunakan dan layak diproduksi secara massal atau disebarluaskan". Dengan uji ini akan didapatkan bukti yang 
kuat untuk mendapatkan rekomendasi agar kamus ini dapat diproduksi secara massal atau disebarluaskan.

\section{Perencanaan Desain Produk}

Desain produk awal yang peneliti rencanakan adalah sebagai berikut:

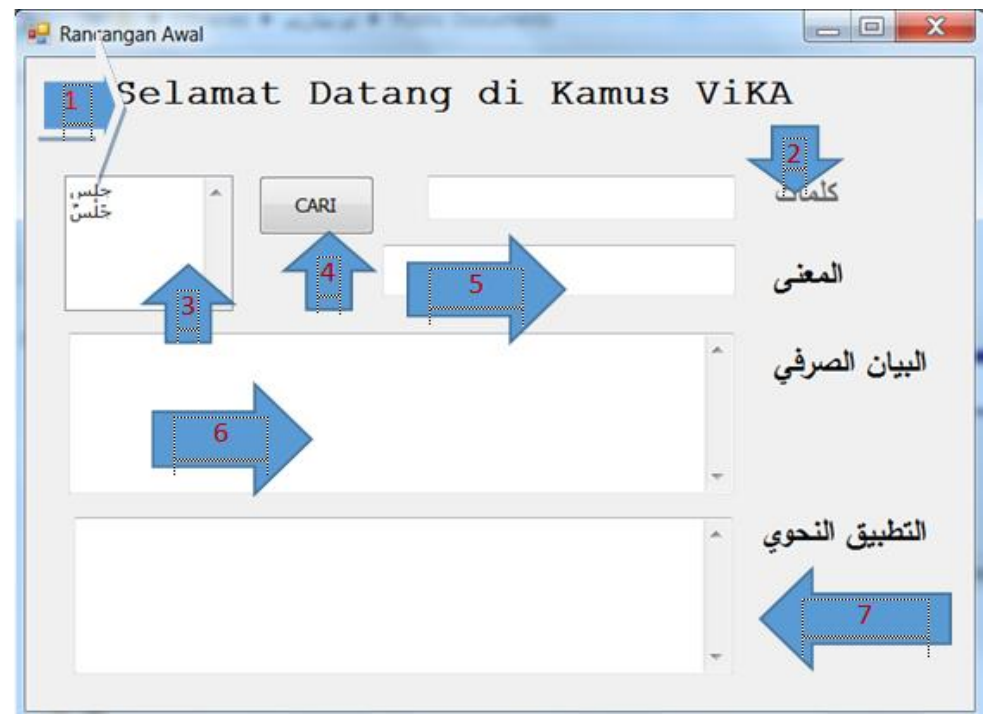

Gambar 1. Rencana Desain Produk Awal

Keterangan:

a. Nomor satu menunjukan textbox kalimat penyambutan bagi yang hendak menggunakan kamus

b. Nomor dua menunjukan textbox yang digunakan untuk memasukan kata yang hendak dicari

c. Nomor tiga menunjukan listbox yang berisi daftar entri kosakata kamus secara urut

d. Nomor empat menunjukan buttonclick (tombol) yang bertugas s fungsi bagi textbox makna kata, makna kreasi, dan makna aksi

e. Nomor lima menunjukan textbox untuk menunjukan makna kata secara harfiah

f. Nomor enam menunjukan textbox untuk menunjukan makna kata yang terkreasikan, dalam hal ini adalah kajian shorofnya

g. Nomor tujuh adalah textbox untuk menunjukan makna kata yang diaksikan, dalam hal ini adalah yang ditinjau dari segi nahwunya. 


\section{Validasi Desain}

Setelah tim peneliti mempresentasikan rancangan desain awal kamus ViKA kepada mahasiswa PBA Semester 5, peneliti mendapatkan masukan untuk mengaktifkan fungsi doubleclick pada listbox, karena jika kata yang dicari hurufnya sama tapi harokatnya beda itu akan menyulitkan dalam mengetik kosakata yang hendak dicari. Kemudian, setelah didiskusikan kembali bersama tim maka peneliti sepakat untuk memberikan fungsi doubleclick pada listbox sehingga ketika melakukan pencarian yang hurufnya sama seperti kata dasar namun harakatnya berbeda pengguna bisa langsung menyortirnya pada listbox. Kata dalam listbox tersebut juga bisa langsung diklik oleh pengguna tanpa mengetiknya kembali, dan pada textboxs (المعنى, البيان) الصرفي, التطبيق النحوي akan muncul makna sesuai yang dimaksud oleh pengguna. Selain itu, tim peneliti juga sepakat untuk mengganti nama tombol CARI dengan ViKA. Sebagaimana berikut:

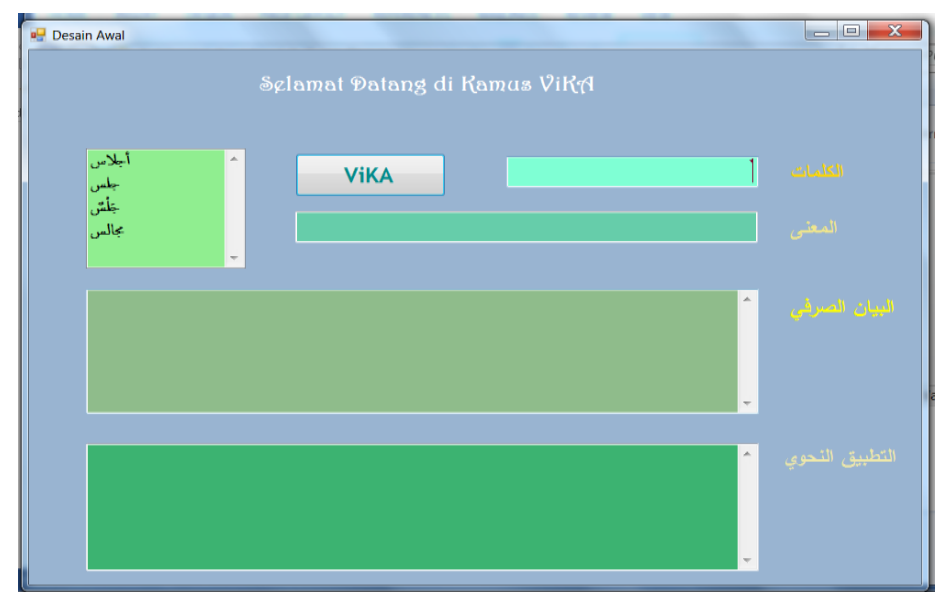

Gambar 2. Validasi Desain Rencana Produk

\section{Metode Rancangan Eksperimen Menguji}

Metode rancangan yang peneliti gunakan untuk eksperimen adalah Comprehensive Design \& Development Projects yaitu metode rancangan yang menghasilkan produk dan penelitian terkait keefektifan produk, dengan proyek tujuannya membuat produk sesuai kebutuhan pengguna, dan metode- metode yang diawali melalui studi kasus, kemudian menganalisis data, kemudian melakukan penilaian terhadap produk (evaluasi sebelum uji 
pemakaian), uji coba produk ke lapangan, melakukan wawancara untuk menguatkan data sebelumnya.

Hal tersebut dikarenakan peneliti melakukan studi kasus terlebih dahulu sebelum membuat desain kamus ViKA. Pembuatan desain kamus ViKA ini merupakan Project Emphasis (proyek tujuan) untuk membuat desain kamus yang sesuai kebutuhan (Comprehensive Design). Pembuatan desain kamus yang sesuai kebutuhan diketahui setelah melakukan analisis data (Content Analysis), yang datanya didapatkan dari angket Pra-ViKA.

Setelah desain kamus dibuat, maka dilakukanlah evaluasi terhadap kamus tersebut setelah melalukan uji coba produk (Evaluation) kepada dosen pembimbing dan temanteman. Evaluasi dilakukan berdasarkan dari masukan yang diberikan oleh dosen dan teman-teman untuk kemudian melakukan perbaikan. Setelah dilakukan perbaikan terhadap kamus, maka kemudian melakukan uji coba pemakaian kepada sampel (Field Observation). Dari uji coba terhadap sampel ini akan didapatkan data terkait tidak atau efektifnya kamus ViKA dari angket Pasca ViKA. Data yang didapat dari angket pra dan pasca ViKA dikuatkan dengan melakukan wawancara (In-Depth Interview).

\section{Desain Awal Produk}

Berikut adalah desain awal produk kamus ViKA:

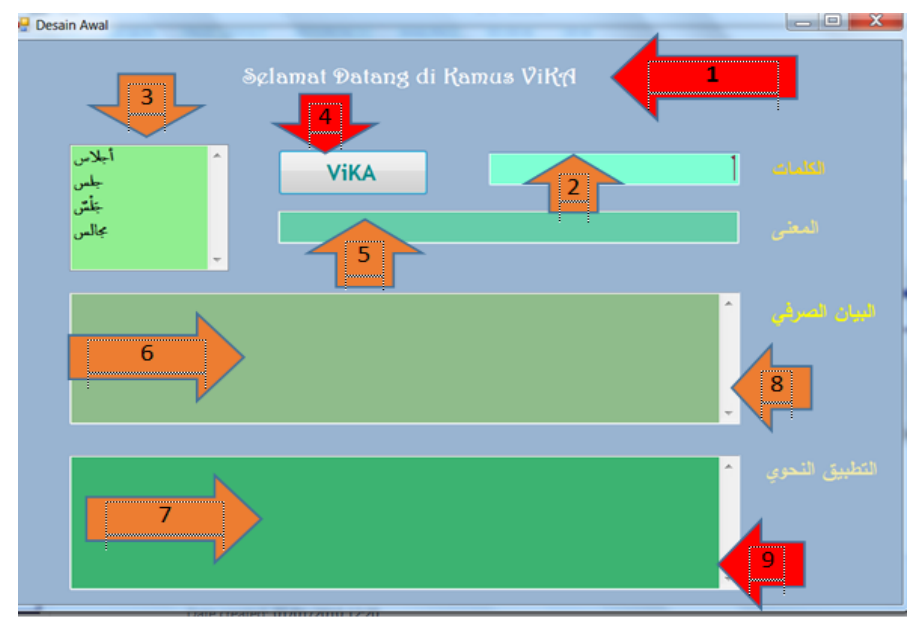

Gambar 3. Desain Awal Produk 


\section{Keterangan:}

1. Nomor satu menunjukan textbox kalimat penyambutan bagi yang hendak menggunakan kamus

2. Nomor dua menunjukan textbox yang digunakan untuk memasukan kata yang hendak dicari

3. Nomor tiga menunjukan listbox yang berisi daftar entri kosakata kamus secara urut

4. Nomor empat menunjukan buttonclick (tombol) yang bertugas sebagai penjalan fungsi bagi textbox makna kata, makna kreasi, dan makna aksi

5. Nomor lima menunjukan textbox untuk menunjukan makna kata secara harfiah

6. Nomor enam menunjukan textbox untuk menunjukan makna kata yang terkreasikan, dalam hal ini adalah kajian sharafnya

7. Nomor tujuh adalah textbox untuk menunjukan makna kata yang diaksikan, dalam hal ini adalah yang ditinjau dari segi nahwunya

8. Nomor delapan dan sembilan merupakan scroll vertical yang berfungsi untuk menurunkan baris teks yang selanjutnya.

dan berikut adalah tampilan ketika melakukan pencarian:

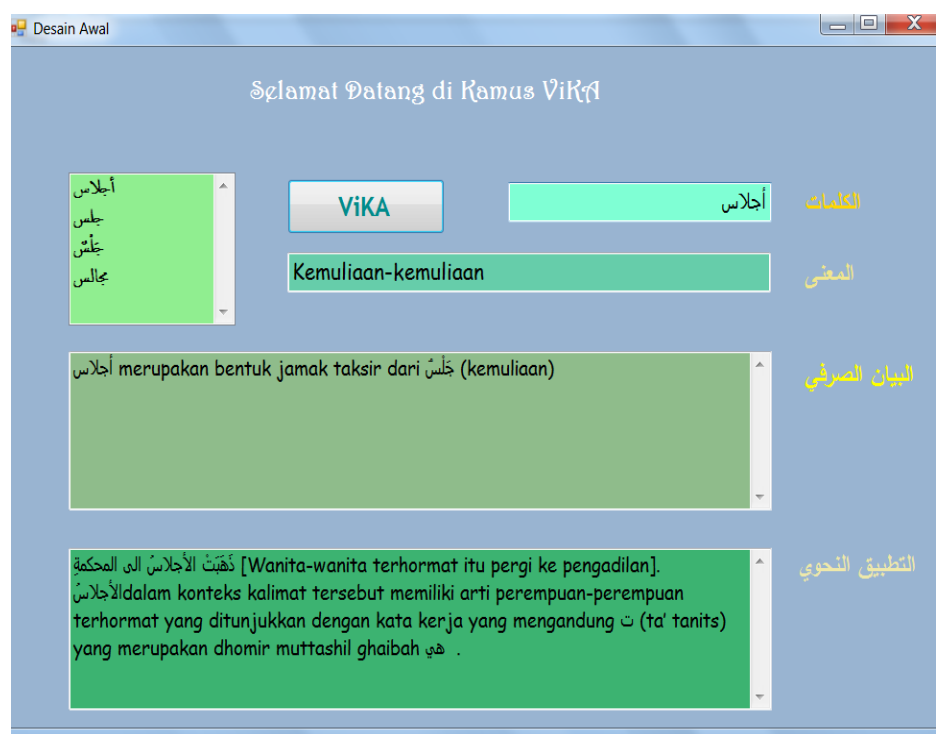

Gambar 4. Tampilan Pencarian

dengan mengeklik tombol ViKA maka makna kata yang dicari jika terdapat dalam listbox akan ditampilkan sebagaimana tampilan di atas. Selain dengan mengeklik tombol ViKA, 
pencarian juga bisa dilakukan dengan mengeklik dua kali pada listbox, hal ini dimaksudkan untuk memudahkan pengguna dalam melakukan pencarian kosakata yang hurufnya sama tapi memiliki harakat yang berbeda. Dalam hal ini peneliti memasukan entri kosakata dasar tanpa harakat agar mempermudah dalam memasukan entri karena kosakata dalam listbox dibuat urut maka kosakata dengan kata dasar atau huruf yang sama yang berbeda harakatnya akan berada di bawah kata dasar tersebut. Sehingga pengguna tinggal mengeklik dua kali kosakata yang ada dalam listbox tersebut (tanpa perlu menuliskan entri ke pencarian) untuk menampilkan makna kosakata tersebut, sebagaimana berikut:

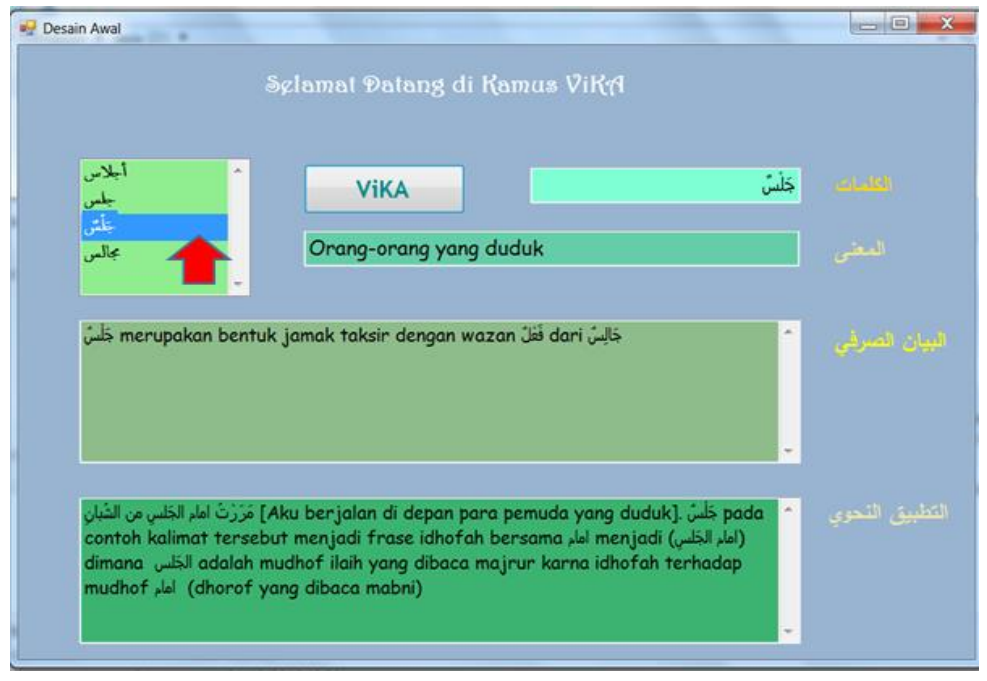

Gambar 5. Tampilan Pencarian Kosakata

Highlight biru yang ditunjuk anak panah tersebut menunjukan bahwa pencarian عَلْسُ Kasakata dilakukan dengan menggunankan fungsi doubleclick pada listbox. Kata memiliki huruf yang sama dengan جلس namun berbeda harakat, jika hendak melakukan pencarian untuk بَسْسُ maka pengguna harus memasukan entri dengan harakat.Maka untuk mempermudah pengguna terhadap kosakata yang sama hurufnya dengan huruf dasar namun berbeda harakat, peneliti membuat kamus ini dengan tidak memasukan harakat pada kata dasar yang lazim dan mengaktifkan fungsi doubleclick pada item-item (entri) di listbox agar ketika melakukan pencarian terhadap kosakata yang berhuruf sama dengan kata dasar yang lazim tapi berbeda harakatnya bisa dilakukan dengan mengeklik dua kali pada kosakata tersebut. 
Selain itu, kamus ViKA tersebut juga sudah dilengkapi dengan fungsi enter dan MessageBox, sehingga ketika melakukan pencarian sebagaimana gambar 4 selain dengan mengeklik tombol ViKA bisa juga langsung dengan mengeklik tombol enter pada keyboard. Sedangkan, fungsi MessageBox merupakan fungsi yang muncul (kotak pesan) apabila kata yang dicari tidak ditemukan (tidak terdapat dalam listbox).

\section{Hasil Pengujian Tahap I}

Berdasarkan hasil diskusi yang dilakukan oleh tim peneliti bersama dosen pembimbing dan ahli IT. Hasil pengujian tahap pertama ini menghasilkan beberapa masukan yang membangun, yaitu:

1. Dari dosen Pembimbing

Dari dosen pembimbing peneliti disarankan untuk mengikuti masukan yang diberikan oleh IT terkait dengan desain kamus ViKA. Sedangkan untuk substansinya (entri kamus), karena sebelumnya peneliti sudah mendiskusikan dengan ahli bahasa (dosen pembimbing) sebelum akhirnya disetujui untuk dijadikan entri kamus dalam rancangan dan validasi desain, maka dalam hal ini daftar entri sudah tidak ada masalah dan bisa dimasukkan sebagai daftar entri dalam Revisi Kamus ViKA.

2. Dari ahli IT

Dari ahli IT peneliti disarankan untuk memberikan halaman Home, yang nantinya terdapat tombol-tombol untuk masuk ke beberapa form seperti; form Tentang, form Biografi, form Petunjuk, dan form Kamus. Saran tersebut menjadi dasar peneliti untuk merevisi produk kamus ViKA.

\section{Revisi Produk}

Berikut adalah desain kamus yang peneliti sepakati bersama yang digunakan uji lapangan terhadap sampel: 


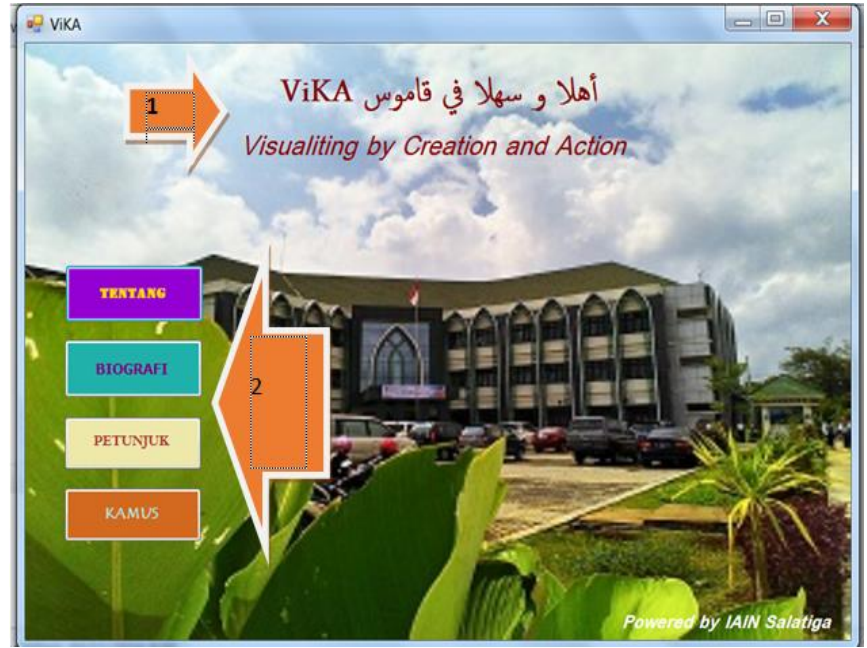

Gambar 7. Halaman home Kamus

Tampilan di atas merupakan halaman home dari kamus yang berisi kalimat penyambutan (anak panah no.1) dan tombol-tombol (anak panah no.2) untuk masuk ke form-form yang terkait:

\section{Form Tentang}

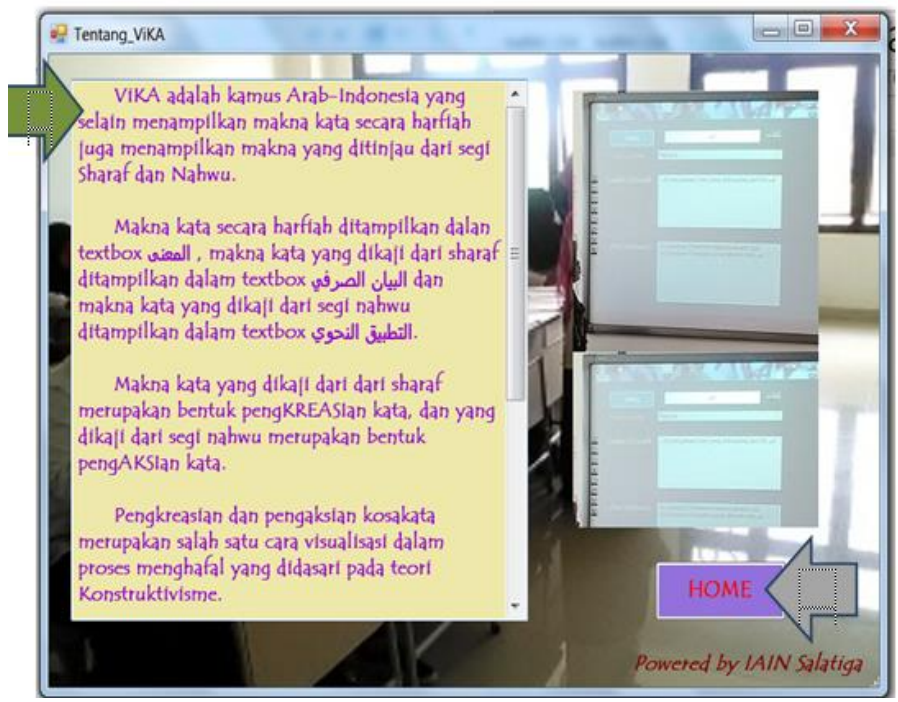

Gambar 8. Form 'Tentang'

Tampilan di atas merupakan form 'Tentang' kamus ViKA, form ini berisi ulasan singkat terkait produk kamus ViKA ini, meliputi; jenis kamus(Arab-Indonesia), 
spesifikasi produk, dan alasan penamaan ViKA . Pada form ini terdapat tombol HOME untuk kembali ke halaman utama (Home).

2. Form Biografi

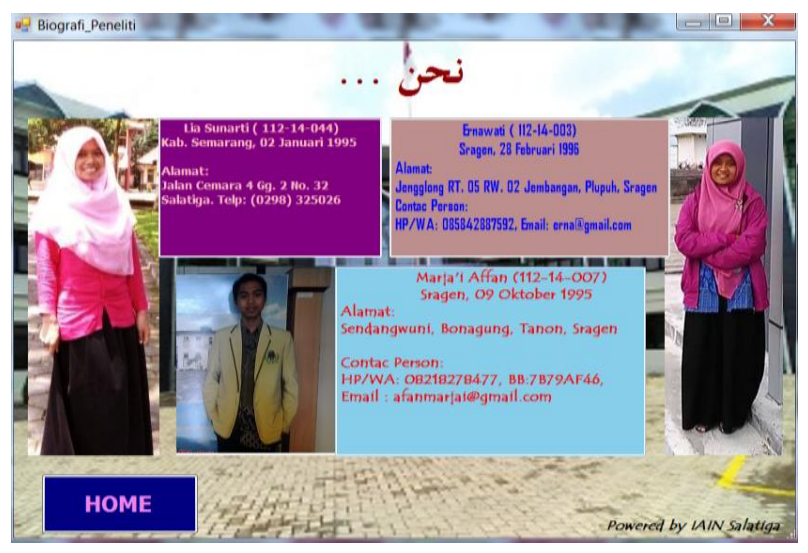

Gambar 9. Form Biografi

Tampilan di atas merupakan form biografi yang berisi data-data singkat identitas peneliti, meliputi: nama lengkap, tempat dan tanggal lahir, dan juga contac person. Dalam form ini juga terdapat tombol HOME untuk kembali ke Menu (halaman utama/home) sebagaimana form yang lain.

\section{Form Petunjuk}

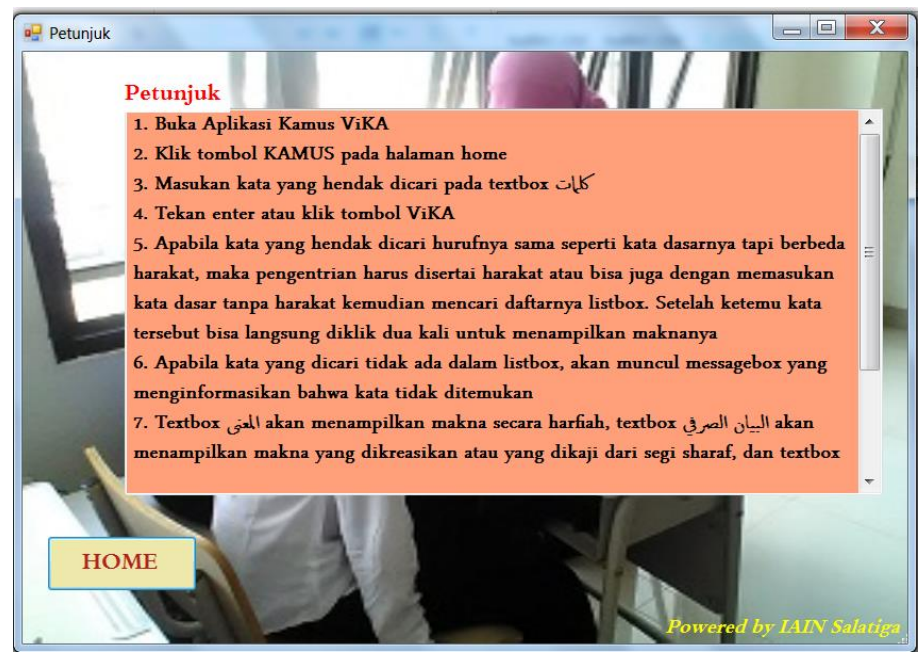

Gambar 10. Form 'Petunjuk'

Tampilan di atas merupakan form 'Petunjuk' yang berisi tentang petunjuk penggunaan kamus ViKA ini mulai dari tombol pada halaman home sampai cara 
pencarian baik melalui texboxt كلمات (pencarian), atau sortirlistbox (melakukan pencarian dengan mencari pada daftar listbox).

\section{Form Kamus}

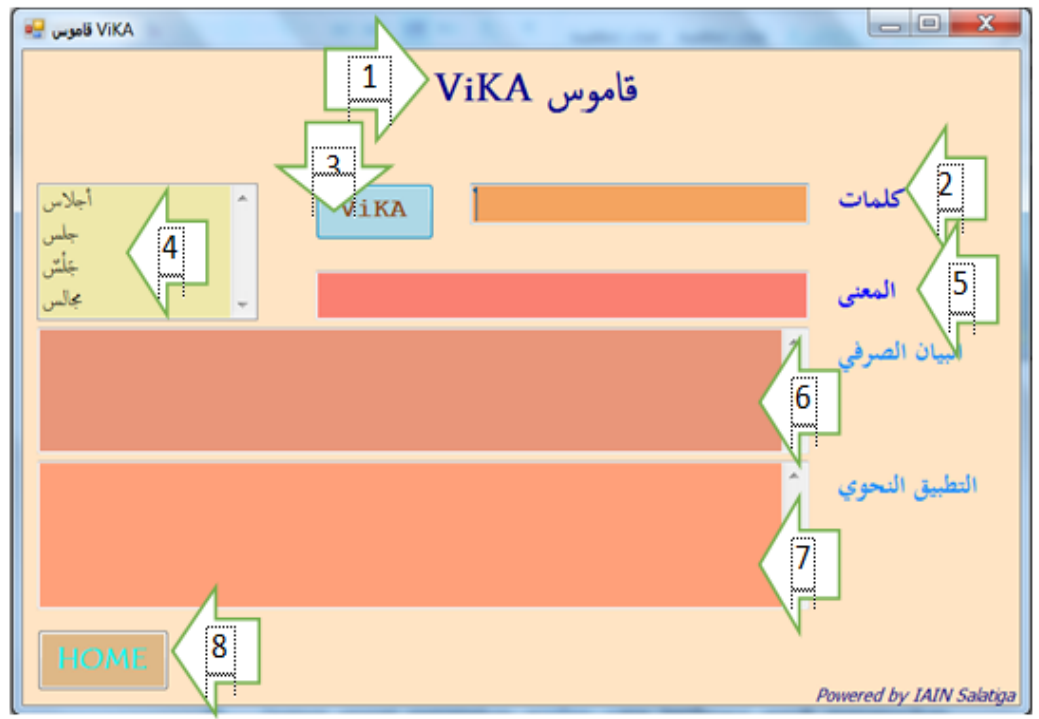

Gambar 11. Form Kamus

\section{Keterangan:}

a. Nomor satu menunjukan label kamus ViKA

b. Nomor dua menunjukan textbox untuk memasukan entri kata

c. Nomor tiga merupakan button sebagai penjalan fungsi pemaknaan

d. Nomor empat merupakan listbox sebagai tempat daftar kata yang dientri

e. Nomor lima merupakan textbox yang berfungsi untuk menampilkan makna kata secara harfiah

f. Nomor enam merupakan textbox yang berfungsi untuk menampikan makna dari kata yang dikreasikan, dalam hal ini adalah yang dikaji dari segi shorofnya

g. Nomor tujuh merupakan textbox yang berfungsi untuk menampilkan makna dari kata yang diaksikan, dalam hal ini adalah yang dikaji dari segi nahwunya.

h. Nomor delapan menunjukan tombol untuk kembali ke halaman home.

Pada produk revisi ini, peneliti menambahkan fungsi highlight item (entri) pada listbox. Fungsi highlight adalah fungsi untuk memberikan highlight (blok) 
pada listbox terhadap kata yang dimasukan untuk dicari. Fungsi tersebut akan mempermudah pengguna dalam mencari kata dengan huruf yang sama namun dengan harakat berbeda, karena entri kata dalam kamus ini disusun urut dan untuk kata dasar yang lazim ditulis tanpa harakat, maka untuk kata yang berhuruf sama tapi berbeda harakat akan terletak dibawah kata dasar lazim tersebut. Melalui fungsi highlight ini, pengguna tinggal memasukan kata yang dicari dengan memasukan kata dasarnya, kemudian menyortirnya (mencari urutannya) melalui listbox dengan menggeser scroll di bawah kata yang di-highlight kemudian dipilih sesuai kata yang dikehendaki dengan mengeklik dua kali pada kata tersebut. Sebagaimana tampilan berikut ini:

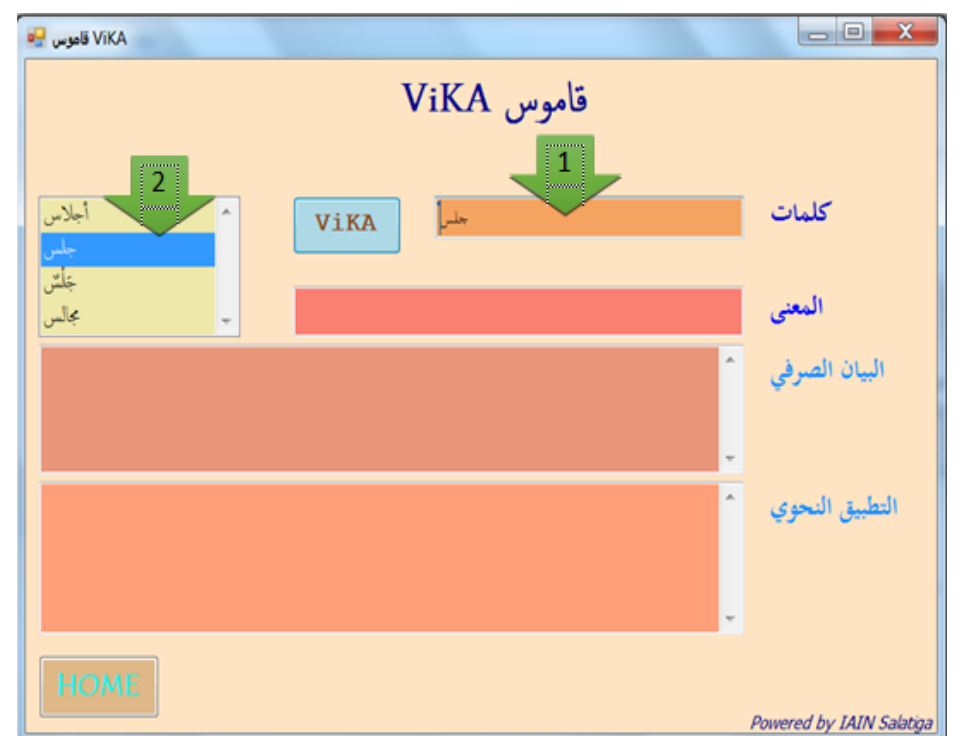

Gambar 12. Tampilan Fungsi Highlight

Tampilan tersebut menunjukan pengeblokkan (no.2) pada item (entri) di listbox terhadap kata yang dicari (no.1). Ketika memasukan kata جلس (kata dasar lazim), maka pada listbox akan me-highligth kata tersebut dan kata جَلْسُ (kata yang hurufnya sama seperti kata dasar tapi berbeda harakat) terletak di bawah kata dasar tersebut. 


\section{Hasil Pengujian Tahap II}

Pada pengujian tahap kedua ini, peneliti melakukan uji coba langsung terhadap sampel, yaitu pada mahasiswa semester 1 jurusan Pendidikan Bahasa Arab (PBA) kelas A dan B. Berdasarkan uji coba tersebut peneliti menghasikan data sebagai berikut :

\section{Angket}

\section{a. Angket Pra ViKA}

Angket Pra ViKA diisi oleh 40 mahasiswa dengan hasil sebagai berikut:

Tabel 1. Hasil Angket Pra ViKa

\begin{tabular}{clc}
\hline No & \multicolumn{1}{c}{ Kriteria } & Jumlah dari 40 \\
\hline $\mathbf{1}$ & Pembelajar Pemula & 33 \\
$\mathbf{2}$ & Penguasan kosakata kurang dari 500 & 29 \\
$\mathbf{3}$ & Pengguna kamus digital & 17 \\
$\mathbf{4}$ & Kurang efektifnya kamus yang sudah ada untuk & 27 \\
& memahamkan kosakata secara mendetail & \\
\hline
\end{tabular}

Hasil tersebut diperoleh setelah dilakukan pengkodingan terhadap keseluruhan data yang ada. Pengkodingan terebut peneliti lakukan untuk menyelaraskan masalah yang terkait dengan hasil studi kasus (mahasiswa PBA semester 1 adalah pembelajar pemula), sehingga data-data yang lain yang diperoleh dari angket yang kurang berkorelasi dengan tujuan dan tidak relevan untuk diuji signifikasi tidak peneliti gunakan.

Dengan data tersebut peneliti melakukan uji signifikasi dua-ekor, karena pada uji signifikasi ini peneliti menggunakan z-score dari suatu statistik S pada kedua ujung. Penentuan $z$-score-nya dihitung dengan rumus seperti berikut:

$$
z=\frac{\mathrm{S}-\mathrm{M}}{\mathrm{SD}}
$$

Keterangan:

1) z: z-score (titik kosong)

2) S: Sampel 
3) M: Mean

4) SD: Standar Deviasi

$$
\mathrm{Z}: \frac{40-27}{6.8}= \pm 1,91
$$

Menurut pada aturan tata pengambilan keputusan pada distribusi normal, (Sutrisno Hadi, 1981: 320) yang berbunyi:

a) Terima hipotesa pada taraf signifikasi $5 \%$ sekiranya $z$-score dari statistik terletak dalam daerah $-1,96$ dan atau $+1,96$

$$
-1,96<\mathrm{z}<+1,96
$$

b) Tolak hipotesa pada taraf signifikasi $5 \%$ sekiranya $z$-score dari statistik $\mathrm{S}$ terletak pada dan di luar $-1,96$ atau $+1,96$

$$
-1,96 \geq z \geq+1,96
$$

maka hasil studi kasus peneliti (dalam hal ini adalah hipotesis yang muncul sebagai hasil studi kasus ) bahwa "mahasiswa PBA semester 1 adalah pembelajar bahasa Arab pemula dan kamus yang sudah ada belum efektif untuk memahamkan makna kosakata secara mendetail" diterima.

b. Angket Pasca ViKA

Angket Pasca ViKA diisi oleh 40 mahasiswa dengan hasil sebagai berikut:

Tabel 2. Hasil Angket Pasca ViKA

\begin{tabular}{ccc}
\hline No & Kriteria & Jumlah dari 40 \\
\hline $\mathbf{1}$ & Kamus ViKA mudah digunakan & 39 \\
$\mathbf{2}$ & Kamus ViKA bermanfaat & 39 \\
$\mathbf{3}$ & Publikasi kamus ViKA & 40 \\
\hline
\end{tabular}

Hasil tersebut juga peneliti dapatkan melalui pengkodingan terhadap keseluruhan data yang peneliti dapatkan. Pengkodingan ini dilakukan agar uji signifikasi terhadap keefektifan kamus ViKA didasari data-data yang relevan.

Dengan cara yang sama seperti yang dilakukan pada angket Pra ViKA maka diperoleh: 


$$
\begin{gathered}
\text { M: } \frac{39+39+40}{3}=39.3 \\
\text { SD: } \sqrt{\{(39-39,3)+(39-39,3)+(40-39,3)\}^{2}:(3-1)} \\
\text { SD: } \sqrt{0,67: 2}=0,578 \\
\text { Z: } \frac{40-39.3}{0,578}= \pm 1.21
\end{gathered}
$$

Karena hipotesa diterima apabila $-1,96<\mathrm{z}<+1,96$, maka hasil observasi lapangan penelitian kamus ViKA ini (dalam hal ini adalah hipotesa yang muncul sebagai hasil observasi lapangan) bahwa "kamus ViKA efektif untuk digunakan" diterima.

c. Wawancara

Peneliti menguatkan kedua data tersebut di atas yaitu angket Pra ViKA dan Pasca ViKA dengan melakukan wawancara kepada 10 mahasiswa PBA semester 1

\begin{tabular}{|c|c|c|c|}
\hline No & Kriteria & $\begin{array}{l}\text { Jumlah } \\
\text { dari } 10\end{array}$ & Masukan \\
\hline 1 & Pembelajar pemula & 6 & a. Entri kosakata \\
\hline 2 & $\begin{array}{l}\text { Pentingnya penggunaan } \\
\text { kamus }\end{array}$ & 10 & $\begin{array}{l}\text { kurang banyak } \\
\text { b. Pemaknaan }\end{array}$ \\
\hline 3 & $\begin{array}{l}\text { Kurangnya keefektifan } \\
\text { kamus yang sudah ada }\end{array}$ & 7 & $\begin{array}{l}\text { harus } \\
\text { diperluas lagi }\end{array}$ \\
\hline 4 & Keefektifan kamus ViKA & 10 & \\
\hline
\end{tabular}
yang terbagi antara kelas A dan B. Berikut data hasil wawancara yang peneliti peroleh:

Tabel 3. Hasil Wawancara

Data hasil wawancara tersebut hanya sebagai penguat data angket dan untuk mendapatkan masukan yang membangun untuk perbaikan kamus ini. Dari hasil wawancara ini peneliti mendapatkan masukan untuk memperbanyak entri kosakata kamus dan memperluas pemaknaan Kreasi dan Aksi. Tentunya masukan tersebut akan peneliti jadikan dasar untuk perbaikan kamus, jika penelitian ini direkomendasikan oleh pihak yang berwenang. 


\section{Produk Kamus ViKA}

Dalam pembahasan produk ini, menguraikan mengenai spesifikasi produk kamus ViKA. Berikut adalah desain produk kamus ViKA terakhir yang ditetapkan sebagai produk peneliti:

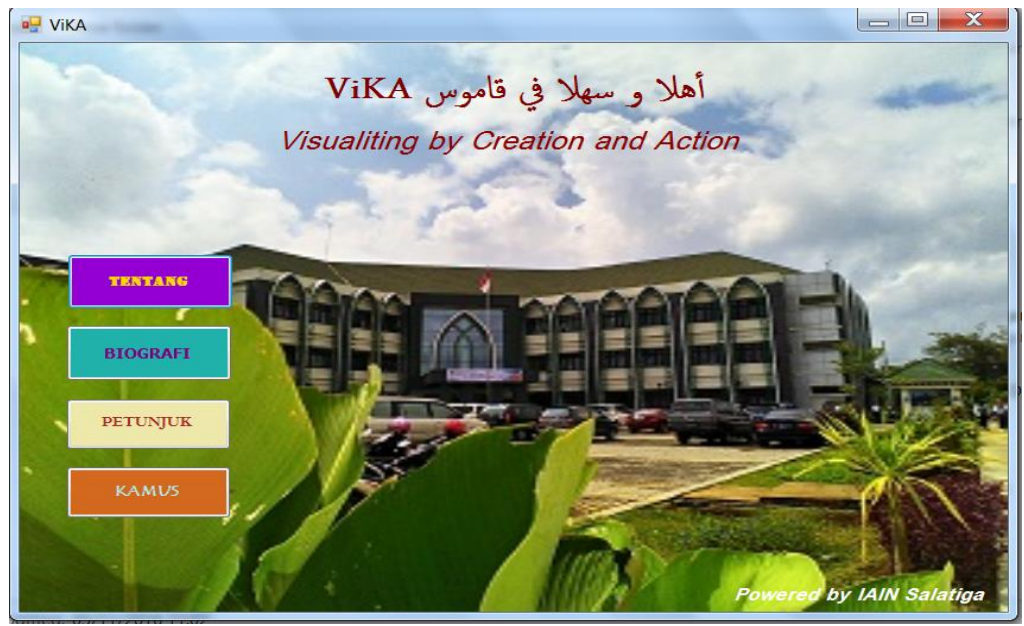

Gambar 13. Desain Kamus Vika Terakhir

Spesifikasi kamus ViKA ini adalah:

1. Hanya bisa bekerja pada sistem operasi Windows saja, sistem operasi lain seperti Linux, Macintos, dan Apple tidak bisa digunakan untuk menjalankan aplikasi ini. Hal ini dikarenakan software yang digunakan untuk membuat kamus ini yaitu Visual Basic 2010 Express merupakan software yang dikembangkan oleh Microsoft yang beroperasi hanya pada lingkungan Windows.

2. Kamus ini baru berisi 4 kosakata keseharian yang sering digunakan, serta penjelasan nahwu dan sharafnya masih dalam satu topik.

3. Kamus ViKA ini tidak perlu dilakukan peng-install-an, setelah di-copy dan dibuka di komputer atau laptop kamus ini bisa langsung digunakan.

\section{Simpulan}

Berdasarkan studi kasus, hasil percobaan, dan uji lapangan kamus digital ViKA, maka dapat ditarik beberapa kesimpulan bahwa mahasiswa PBA Semester 1 IAIN Salatiga adalah pembelajar bahasa Arab pemula, yang membutuhkan media yang representatif untuk memahamkan makna kosakata bahasa Arab secara mendetail. Kamus ViKA (Visualitation by Creation and Action) merupakan sebuah kamus digital Arab-Indonesia, 
yang dirancang sedemikian rupa untuk menjadi media yang representatif bagi pembelajaran bahasa Arab, terutama pembelajar pemula.

\section{Daftar Rujukan}

Bagus Handoko. Buat Aplikasi Kamus Menggunakan Visual Basic,URL: http://coretanlusuh.blogspot.co.id/2013/03/buat-aplikasi-kamus-menggunakan-visual.html. (13 September 2016)

Daymon, Christine dan Immy Holloway. Metode-Metode Riset Kualitatif dalam Public Relations \& Marketing Communications. Yogyakarta: Penerbit Bentang, 2008.

Dictionary Tutorial Part 1 - Visual Basic .NET.htm (11 September 2016)

Emzir. Metodologi Penelitian Pendidikan Kualitatif \& Kuantitatif Edisi Revisi. Jakarta: PT. Raja Grafindo Persada, 2008.

Habibi, Burhan Yusuf dan Muhammad Fahrun Nadhif. Syamila. Semarang: Pustaka Amanah, 2014.

Hadi, Sutrisno. Metodologi Research. Yogyakarta: Yayasan Penerbitan Fakultas Psikologi Universitas Gadjah Mada, 1981.

Hafidz, Muhammad. Dasar-Dasar Ilmu Nahwu. Yogyakarta: Mitra Cendekia, 2009.

Kukla, Andre. Konstruktivisme Sosial Dan Filsafat Ilmu. Yogyakarta: Penerbit Jendela, 2003.

Ma’sum, Muhammad. Al-Amtsilah At-Tashrifiyah. Semarang : Wicaksono, tt.

Mahmud, Khoirotul Irawati dan Hanifuddin Magasin. Cara Belajar Cepat Abad 21 Metode Hanifida Brain Based Learning Modell Konstruktivisme cet XII. Jombang: CV. Percatakan Fajar, 2015.

Munawwir, Ahmad Warson. Al-Munawwir (Kamus Arab -Indonesia) cet XIV. Surabaya: Pustaka Progressif, 1997.

Pandia, Henry. Pemrograman dengan Visual Basic. Jakarta: Erlangga, 2006.

Sudjana. Metoda Statistika. Bandung : PT. TARSITO, 2015.

Sugiono, Metode Penelitian Kualitatif dan Kuantitatif dan Dasar-Dasar Pemrogaman Visual Studio 2010, Budi Permana. Pdf. , R \& D. : Bandung: Alfabeta, 2010. 